\title{
Prediction of Surgical Outcome as Regards Stone Free Rate and Complications after Percutaneous Nephrolithotomy Using S. T. O. N. E. versus sResc Scoring Systems
}

\author{
AHMED S. HEGAZY, M.D.; MOHAMED SHABAYEK, M.D. and \\ ABDELRAHIM G.A. ELSHERBINY, M.Sc.
}

The Department of Urology, Faculty of Medicine, Ain Shams University

\begin{abstract}
Background: Nephrolithiasis is a major worldwide source of morbidity, constituting a common urological disease affecting $10-15 \%$ of the world population.

Aim of Study: To compare the S.T.O.N.E versus sResc scoring system in prediction of the surgical outcome as regards stone free rate and complication after PCNL.

Patients and Methods: A prospective randomized clinical study conducted in Department of Urology, Faculty of Medicine, Ain Shams University Hospitals. Study period was 6 months from 3-2020 till 9-2020.

Results: STONE total score involved size, tract length, degree of obstruction, number of involved calyces and stone density. STONE score was $6.8 \pm 1.7$. S-ReSC total score was 3.1 \pm 1 .6. A significant statistical association between both scores was found $\left(\chi^{2}: 119.681, p<0.001\right)$. Mean STONE score was $6.19 \pm 1.20$ compared to $7.92 \pm 1.89$ in free and residual group of patients respectively $(t: 4997 ; p<0.0001)$. Mean $S$ ReSC score was $2.14 \pm 0.88$ compared to $4.76 \pm 1.30$ in free and residual group of patients respectively $(t: 4997 ; p<0.0001)$. Both scores were higher significantly in patients with residual stones. The ROC curve shows that the best cut off point for S-ReSC score to detect residual free rate was found $>2$ with sensitivity $100 \%$, specificity $76.19 \%$ and Area Under Curve (AUC) $95 \%$ while the best cut off point for STONE score to detect residual free rate was found $>6$ with sensitivity $70.3 \%$, specificity $68.3 \%$ and Area Under Curve (AUC) 76.4\%.

Conclusion: Both S-ReSC and S.T.O.N.E Nephrolithometry Scores can be used to stratify the complexity of renal stone before PCNL to predict the stone clearance and complication.
\end{abstract}

Key Words: Stone free rate - PCNL - Nephrolithotomy S. T. O. N. E-sResc.

\section{Introduction}

NEPHROLITHIASIS is a major worldwide source of morbidity, constituting a common uro-

Correspondence to: Dr. Abdelrahim G.A. Elsherbiny, E-Mail: abdelrahim.elsherbiny@gmail.com logical disease affecting $10-15 \%$ of the world population [1,2]. It is an expanding problem associated with major economic and health consequences. Consistent technical advancements provide surgeons and patients with several options for the treatment of renal calculi, including extracorporeal Shock Wave Lithotripsy (SWL), Percutaneous Nephrolithotomy (PCNL), Retrograde Intrarenal Surgery (RIRS), and conventional open surgery $[3,4]$.

Percutaneous Nephrolithotomy (PCNL) is generally considered a gold standard in renal stones $>2 \mathrm{~cm}$ or lower calyceal $>1 \mathrm{~cm}$ offering high stonefree rates after the first treatment as compared to the other minimal invasive lithotripsy techniques. However, serious complications although rare should be expected following this percutaneous procedure [5].

Perioperative bleeding, urine leak from nephrocutaneous tract, pelvicalyceal system injury, and pain are individually confronted complications after PCNL. Thus a universally accepted scoring system for use in percutaneous management of nephrolithiasis such as; S.T.O.N.E. nephrolithometry score, and Renal Stone Complexity (S_ReSC) score have been described to enable appropriate counselling of patients, minimize adverse outcomes, and provide a means of standardized reporting of stone complexity and patient outcomes [6,7].

S.T.O.N.E. nephrolithometry score, usesnoncontrast-enhanced Computed Tomography (CT) scans parameters to describe and classify the most relevant features that affect the percutaneous management of renal calculi [8]. It represents five variables: Stone size, tract length, degree of obstruction, number of involved calyces, and stone 
essence (stone density). On the basis of these variables, a score of 5-13 can be calculated; a higher score correlates with higher stone complexity [9].

The S-ReSC scoring system is based solely on stone distribution within the collecting system and does not take into account any patient characteristic nor baseline renal anatomy [10]. They devised a 9point system which is determined with preoperative CT, with 1 point assigned to 9 specific pelvic and calyceal locations. A score of 1 to 2 is considered low, 3 to 4 is medium, and $\geq 5$ is high. The score is assigned by adding the cumulative sites involved [8].

\section{Patients and Methods}

A prospective randomized clinical study conducted in Department of Urology, Faculty of Medicine, Ain Shams University Hospitals. Study period was 6 months.

Inclusion criteria included: Renal stone $>2 \mathrm{~cm}$, lower calyceal stone $>1 \mathrm{~cm}$, and previously failed ESWL to remove the stone. Exclusion criteria were associated congenital anomalies pelvi-calyceal system e.g. ectopic or malrotated kidney, comorbidity interfering with prone position (morbid obesity, COBD), bleeding disorders/uncorrected coagulopathy, untreated UTI, renal tumors, pregnancy, access prevented by surrounding organs e.g. splenomegaly or by the bowelor patients unfit for general anesthesia.

All patients candidates for PCNL were evaluated for S.T.O.N.E. score as well as S-Resc score before undergoing PCNL.

Pre-operative evaluation included comprehensive medical and surgical history from all patients included in our study, full pre-operative laboratory tests including CBC, PT, PTT, INR serum creatinine, ALT, sodium, potassium, pre-operative KUB will be done, and pre-operative NCCT will be performed. S.T.O.N.E and sResc scoring system were calculated for each case.

Operative evaluation included operative time, need for intraoperative blood transfusion, any cardiovascular complication, any related operative complication e.g. perforation of the renal collecting system, colonic injury, intraoperative bleeding.

Post-operative evaluation included postoperative change in hemoglobin and hematocrit value and need for blood transfusion, post-operative radiological evaluation will be done using KUB and/or CT to determine stone free rate, duration of hospital stay, and post-operative related complications e.g. post-operative fever, need for blood transfusion, urinary leakage and its grading according to ClavienDindo.

\section{Statistical analysis:}

Data were computed and analyzed using IBM SPSS software package version 20.0. (Armonk, NY: IBM Corp) Qualitative data were described using number and percent. Chi-square testwas used for categorical variables, to compare between different groups. Wilcoxon signed ranks testfor abnormally distributed quantitative variables, to compare between two periods. Student $t$-test for normally distributed quantitative variables, to compare between two studied groups. Mann Whitney testfor abnormally distributed quantitative variables, to compare between two studied groups.

\section{Results}

In our study 100 PCNL procedures were done. All were done in prone position with a mean age of $43.8 \pm 11.7$ (range from 20 to 66) and BMI of $29.3 \pm 2.4$ (range from 23 to 35 ). The study included 42 females and 58 males Fig. (1).

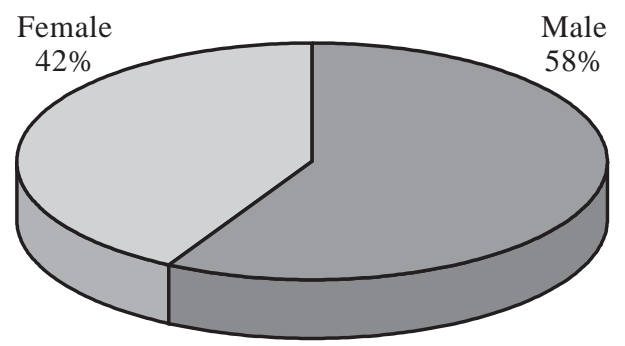

Fig. (1): Gender distribution.

As regards the past medical history 67 patients were medically free, whereas 33 patients had history of associated comorbidities (Table 1).

Table (1): Associated comorbidities.

\begin{tabular}{lll}
\hline & $\mathrm{N}$ & $\%$ \\
\hline DM: & & \\
$\quad$ Not diabetic & 80.0 & 80.0 \\
Diabetic & 20.0 & 20.0 \\
HTN: & & \\
Not hypertensive & 84.0 & 84.0 \\
HTN & 16.0 & 16.0 \\
Cardiac: & & \\
Not cardiac & 93.0 & 93.0 \\
Cardiac & 7.0 & 7.0 \\
Previous surgery: & & \\
No & 73.0 & 73.0 \\
Yes & 27.0 & 27.0 \\
$\quad$
\end{tabular}


Diabetes mellitus was found in 20 patients 16 patients were receiving anti-hypertensive medications and 7 patients were cardiac. 27 patients had previous surgical interventions.

Stonerelated factors included stone side; 51 patients had left side stones; 48 patient had right side stones. Pelvicalycial stone were the majority, reaching $80 \%$ of the patients. Pelvic stones were found in 10 patients and Calyceal stones in 10 patients Fig. (2).

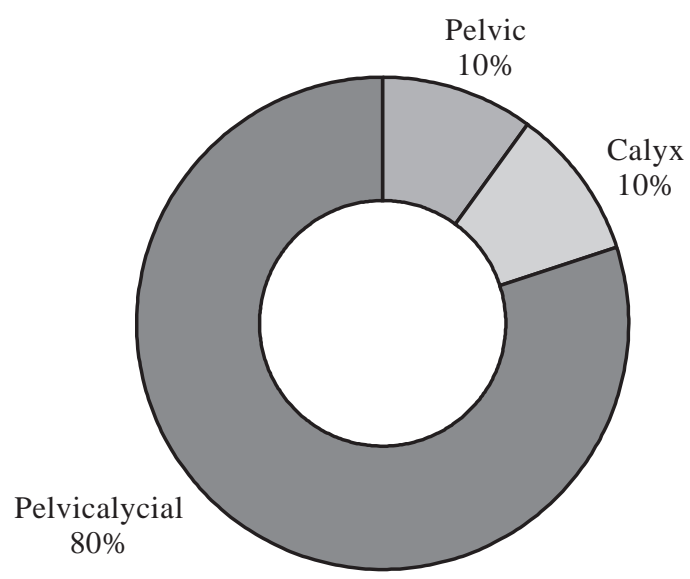

Fig. (2): Stone location.

Majority (47\%) of patients had stone size $<400 \mathrm{~mm}^{2}$. Stonesize was $526.4 \pm 338.1$ (mean \pm $\mathrm{SD})$ with range of $120-1674 \mathrm{~mm}^{2}$ (Table 2).

Table (2): Stone size.

\begin{tabular}{lcl}
\hline Size $\left(\mathrm{mm}^{2}\right)$ & Count & $\%$ \\
\hline$<400$ & 47 & 47.0 \\
$400-799$ & 33 & 33.0 \\
$800-1199$ & 14 & 14.0 \\
$\geq 1200$ & 6 & 6.0 \\
\hline
\end{tabular}

Stone density was as the following, 53 patients had stone essence between 500-999HU, 33 patients had stone essence $\geq 1000 \mathrm{HU}$. Stone density was $841.9 \pm 313.9$ (mean \pm SD) with range of 320-1546 HU (Table 3).

Table (3): Stone density.

\begin{tabular}{lcl}
\hline Density & Count & $\%$ \\
\hline$<500$ & 14 & 14.0 \\
$500-999$ & 53 & 53.0 \\
$1000-1499$ & 30 & 30.0 \\
$\geq 1500$ & 3 & 3.0 \\
\hline
\end{tabular}

Tract length was $99 \pm 5.2$ (mean \pm SD) with range of $80-12 \mathrm{~mm}$. Degree of obstruction and number of involved calyces were shown in (Table 4).
Table (4): Degree of obstruction and involved calyces.

\begin{tabular}{lll}
\hline & $\mathrm{N}$ & $\%$ \\
\hline Degree of obstruction: & & \\
$\quad$ Nil & 10.0 & 10.0 \\
Minimal & 2.0 & 2.0 \\
Mild & 69.0 & 69.0 \\
Moderate & 15.0 & 15.0 \\
Marked & 3.0 & 3.0 \\
Severe & 1.0 & 1.0 \\
Number of involved calyces: & & \\
1. & 16.0 & 16.0 \\
2. & 45.0 & 45.0 \\
3. & 25.0 & 25.0 \\
Stag horn & 14.0 & 14.0 \\
\hline
\end{tabular}

During radiological evaluation all patients had element of obstruction ranging from minimal in 2 patients, moderate to severe hydronephrosis in 19 patients. Mild hydronephrosis presented in 69\% of the patients.

STONE total score involved size, tract length, degree of obstruction, number of involved calyces and stone density. STONE score was $6.8 \pm 1.7$ with minimum of 5.0 and maximum of 11.0. Majority of STONE grade $(53 \%)$ of the included cases was low grade and $20 \%$ were high grade. S-ReSC total score was $3.1 \pm 1.6$ with minimum of 1 and maximum of 7. S-ReSC Grade was as the following: Majority $(48 \%)$ of the included cases was low grade and $21 \%$ were high grade. To investigate the agreement between both scores, we have done chisquare test. It shows a significant statistical association between both scores $\left(\chi^{2}: 119.681, p<0.001\right)$ (Table 5).

Table (5): STONE and S-ReSC relation.

\begin{tabular}{lllllllll}
\hline & \multicolumn{7}{c}{ S-ReSC total } & Total \\
\cline { 2 - 6 } Stone & 1 & 2 & 3 & 4 & 5 & 6 & 7 & \\
\hline 5 & 10 & 11 & 3 & 2 & 0 & 0 & 0 & 26 \\
6 & 3 & 15 & 6 & 4 & 0 & 0 & 0 & 28 \\
7 & 0 & 7 & 3 & 3 & 2 & 0 & 0 & 15 \\
8 & 0 & 2 & 4 & 4 & 1 & 0 & 1 & 12 \\
9 & 0 & 0 & 0 & 1 & 3 & 3 & 2 & 9 \\
10 & 0 & 0 & 0 & 1 & 4 & 2 & 0 & 7 \\
11 & 0 & 0 & 0 & 0 & 0 & 2 & 1 & 3 \\
\hline Total & 13 & 35 & 16 & 15 & 10 & 7 & 4 & 100 \\
\hline
\end{tabular}

Operative time was $50.2 \pm 19.7$ minutes with minimum of 20 and maximum of 100 minutes. It was estimated from the moment of skin puncturing, so the time consumed in anesthesia, ureteral catheter placement and patient positioning was not considered. The mean operative time was $50.2( \pm 19.7)$ min. with a range (20-100) min. Hb was decreased significantly from 14.6 to 12.4 post-operatively. 
Intra op complications included bleeding (in any quantity) occurred in all cases. Perforation occurred in $32 \%$, colonic injury in $1 \%$, CV events in $1 \%$ and $39 \%$ needed DJ (Table 6).

Table (6): Intra op complications.

\begin{tabular}{lll}
\hline Intra operative complications & $\mathrm{N}$ & $\%$ \\
\hline $\begin{array}{l}\text { Bleeding: } \\
\quad \text { No }\end{array}$ & 0.0 & 0.0 \\
$\quad$ Yes & 100.0 & 100.0 \\
Perforation: & & \\
$\quad$ No & 68.0 & 68.0 \\
Yes & 32.0 & 32.0 \\
Colonic injury: & & \\
$\quad$ No & 99.0 & 99.0 \\
Yes & 1.0 & 1.0 \\
CV event: & & \\
No & 99.0 & 99.0 \\
Yes & 1.0 & 1.0 \\
Need DJ: & & \\
$\quad$ No & 61.0 & 61.0 \\
Yes & 39.0 & 39.0 \\
\hline
\end{tabular}

The hospital stay mean time was $2.51 \pm 1.47$ and range of 1-5 days. Post-operative complications included blood transfusion which was needed in only $3 \%$. Fever occurred in $20 \%$. Leakage in $38 \%$. Hematuria in $40 \%$ and distal obstruction in $15 \%$ of the study patients. Regarding stone free rate, $63 \%$ were stone free and $37 \%$ had residuals Fig. (3).

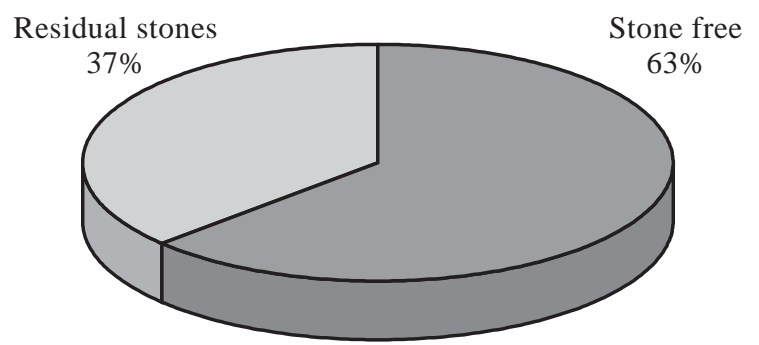

Fig. (3): Stone free rate.

Pelvicalycial stone free rate was $76.2 \%$, pelvic $15.9 \%$ and calyceal in $7.9 \%$. This distribution was statistically significant $\left(\chi^{2}: 6.907, p: 0.032\right)$. Mean STONE score was $6.19 \pm 1.20$ compared to $7.92 \pm$ 1.89 in free and residual group of patients respectively $(t: 4997 ; p<0.0001)$. Mean S-ReSC score was $2.14 \pm 0.88$ compared to $4.76 \pm 1.30$ in free and residual group of patients respectively $(t: 4997$; $p<0.0001)$. Both scores were higher significantly in patients with residual stones.
The ROC curve shows that the best cut off point for S-ReSC score to detect residual free rate was found $>2$ with sensitivity $100 \%$, specificity 76.19\% and Area Under Curve (AUC) 95\% while the best cut off point for STONE score to detect residual free rate was found $>6$ with sensitivity $70.3 \%$, specificity $68.3 \%$ and Area Under Curve (AUC) 76.4\% Fig. (4), (Table 7).

Table (7): Relation between stone free rate and location of the stone.

\begin{tabular}{|c|c|c|c|c|c|c|}
\hline \multirow{3}{*}{\multicolumn{2}{|c|}{ Location }} & \multicolumn{3}{|c|}{ Stone free rate } & \multirow{3}{*}{$\chi^{2}$} & \multirow{3}{*}{$p$} \\
\hline & & Free & \multicolumn{2}{|c|}{ Residual stones } & & \\
\hline & & $\%$ & $\mathrm{~N}$ & $\%$ & & \\
\hline Pelvic & & 15.9 & 0 & 0.0 & 6.907 & 0.032 \\
\hline Calyx & & 7.9 & 5 & 13.5 & & \\
\hline \multicolumn{2}{|c|}{ Pelvicalycial } & 76.2 & 32 & 86.5 & & \\
\hline \multirow{3}{*}{ Score } & \multicolumn{4}{|c|}{ Stone free rate } & \multirow{3}{*}{$t$} & \multirow{3}{*}{$p$} \\
\hline & \multicolumn{2}{|c|}{ Free } & \multicolumn{2}{|c|}{ Residual stones } & & \\
\hline & Mean & SD & Mean & SD & & \\
\hline STONE & 6.19 & 1.20 & 7.92 & 1.89 & 4.997 & $<0.0001$ \\
\hline S-ReSC & 2.14 & 0.88 & 4.76 & 1.30 & 10.866 & $<0.0001$ \\
\hline
\end{tabular}

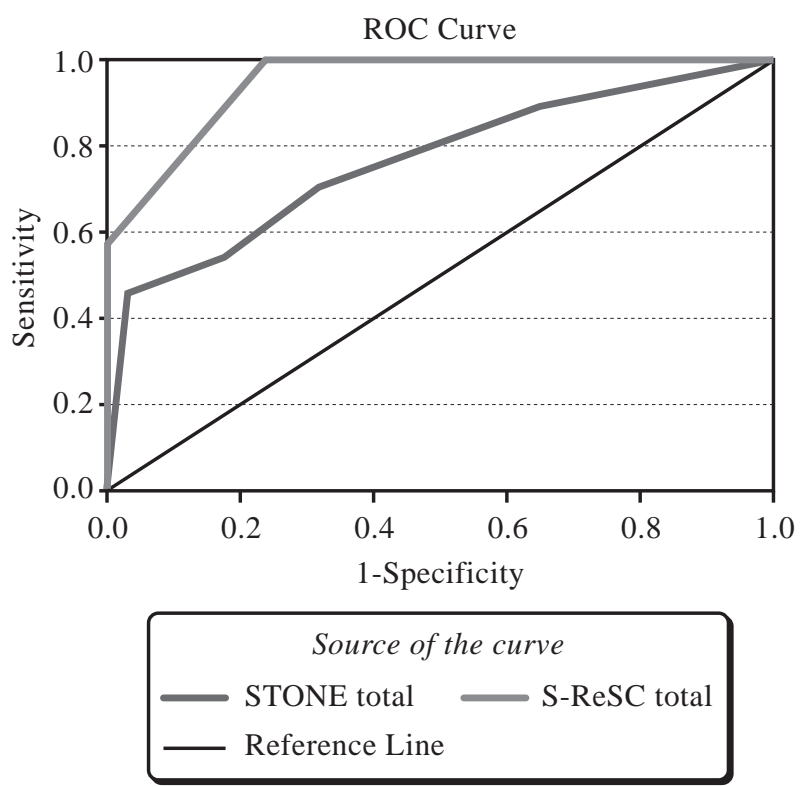

Fig. (4): Receiver Operating Characteristic (ROC) curve for $\mathrm{S}-\mathrm{ReSC}$ score and STONE score as a predictor for residual stone.

\section{Discussion}

Percutaneous Nephrolithotomy (PCNL) is generally considered a gold standard in renal stones $>2 \mathrm{~cm}$ or lower calyceal $>1 \mathrm{~cm}$ offering high stone- 
free rates after the first treatment as compared to the other minimal invasive lithotripsy techniques. However, serious complications although rare should be expected following this percutaneous procedure [5].

In our study 100 PCNL procedures with a mean age of $43.8 \pm 11.7$ (range from 20 to 66 ). The study included 42 females and 58 males. As regards the past medical history 67 patients were medically free, whereas 33 patients had history of associated comorbidities.

Diabetes mellitus was found in 20 patients 16 patients were receiving anti-hypertensive medications and 7 patients were cardiac. 27 patients had previous surgical interventions. Pelvicalycial stone were the majority, reaching $80 \%$ of the patients. Pelvic stones were found in 10 patients and Calyceal stones in 10 patients.

Majority (47\%) of patients had stone size $<400 \mathrm{~mm}^{2}$. Stonesize was 526.4 $\mathbf{3} 38.1$ (mean \pm SD) with range of $120-1674 \mathrm{~mm}^{2} .53$ patients had stone essence between 500-999HU, 33 patients had stone essence $\geq 1000 \mathrm{HU}$. Stone density was 841.9 \pm 313.9 (mean \pm SD) with range of 320-1546 HU. Tract length was 99 \pm 5.2 (mean \pm SD) with range of $80-12 \mathrm{~mm}$.

During radiological evaluation, all patients had element of obstruction ranging from minimal in 2 patients, moderate to severe hydronephrosis in 19 patients. Mild hydronephrosis presented in $69 \%$ of the patients.

STONE total score involved size, tract length, degree of obstruction, number of involved calyces and stone density. STONE score was $6.8 \pm 1.7$ with minimum of 5.0 and maximum of 11.0. S-ReSC total score was $3.1 \pm 1.6$ with minimum of 1 and maximum of 7 .

In our study, operative time was $50.2 \pm 19.7$ minutes with minimum of 20 and maximum of 100 minutes. It was estimated from the moment of skin puncturing, so the time consumed in anesthesia, ureteral catheter placement and patient positioning was not considered. This was relatively less than other series with a mean operative times $60.3 \mathrm{~min}$., $74 \mathrm{~min}$ by Rathee and his colleague, and Sujeet Poudyal and his colleagues respectively [11].

In a study done by Kumar and his colleagues they observed that for every unit of increase in STONE score, the operative time increased by $8.1 \mathrm{~min}(p<0.001)$. In our study, the hospital stay mean was $2.51 \pm 1.47$ and range of $1-5$ days. The length of stay in Kumar et al., study increased by 0.58 days $(p=0.001)$ for every unit of rise in STONE score [2]. Bleeding (in any quantity) occurred in all cases. Perforation occurred in $32 \%$, colonic injury in $1 \%, \mathrm{CV}$ events in $1 \%$ and $39 \%$ needed DJ. Blood transfusion was needed in only $3 \%$. Fever occurred in $20 \%$. Leakage in $38 \%$. Hematuria in $40 \%$ and distal obstruction in $15 \%$ of the study patients.

In our study the complication rate was $25 \%$ the most common post-operative complication was fever. Our results were compatible with El-Nahas and his colleagues, whom they recorded complication rate of $22 \%$ and were not comparable with Resorlu and his colleagues, whom they recorded complication rate of 55\% [12]. El-Nahas et al., 2012 study on 251 patients recorded rate of $27 \%$. Variability in the perioperative complication rates with other series referred to stone complexity, number of procedures done, surgeon experience and the patients' co-morbidities [12].

In our study we found correlation between our results and study done by Poudyal and his colleagues where the complication rate was $27.9 \%$ with the most common complication fever and a study done by Kumar and his colleagues where the complication rate was $22.92 \%$ and the most common complication was fever [2]. We found a correlation between the calculated scores with the perioperative complications. The rate of complications increases with the increase in the calculated scores as indicated by the previous studies.

Regarding stone free rate, $63 \%$ were stone free and $37 \%$ had residuals. Pelvicalycial stone free rate was $76.2 \%$, pelvic $15.9 \%$ and calyceal in $7.9 \%$. This distribution was statistically significant $\left(\chi^{2}\right.$ : 6.907, $p: 0.032$ ). Our stone free rate is comparable to ratios published in Shin et al., 2011 which was $69.9 \%$ and Huang et al., 2005 which was $74.4 \%$ $[13,14]$. Other series showed stone free rate of $87 \%$, $84 \%, 89.2 \%$ and $83 \%$ [15-17] while lower values were shown $56 \%$ and $49 \%$ by (El-Nahas et al., 2012 and Al-kohlany et al., 2005) respectively $[12,18]$. The difference in our stone rate with the other studies may be attributed to the higher stone burden in their studies than in ours.

STONE total score involved size, tract length, degree of obstruction, number of involved calyces, and stone density. STONE score in our study was $6.8 \pm 1.7$ with minimum of 5.0 and maximum of 11.0. Majority $53 \%$ of the included cases was low grade and $20 \%$ were high grade. S-ReSC total score was $3.1 \pm 1.6$ with minimum of 1 and maxi- 
mum of 7. Majority (48\%) of the included cases was low grade and $21 \%$ were high grade. Mean STONE score was $6.19 \pm 1.20$ compared to $7.92 \pm$ 1.89 in free and residual group of patients respectively $(t: 4997 ; p<0.0001)$. Mean S-ReSC score was $2.14 \pm 0.88$ compared to $4.76 \pm 1.30$ in free and residual group of patients respectively $(t: 4997$; $p<0.0001)$. Both scores were higher significantly in patients with residual stones.

In our study, the best cut off point for S-ReSC score to detect residual free rate was found $>2$ with sensitivity $100 \%$, specificity $76.19 \%$ and Area Under Curve (AUC) 95\% while the best cut off point for STONE score to detect residual free rate was found $>6$ with sensitivity $70.3 \%$, specificity 68.3\% and Area Under Curve (AUC) 76.4\%. There are few studies comparing S-ReSC and S.T.O.N.E score in predicting the outcome of PCNL. Yarimoglu andcolleagues study reported mean S.T.O.N.E and S-ReSC scores of $9.7 \pm 1.6$ and $6.2 \pm 2.0$ respectively. The overall stone-free rate was $59 \%$. Both scoring systems were significantly correlated with stone-free status in univariate analysis. S-ReSC score was the only significant independent predictor in multivariate analysis. Their study demonstrated that S-ReSC scoring system could effectively predict post-operative stone-free status for staghorn stones. However, both scoring systems failed to predict complication rates [19].

A recent retrospective study by $\mathrm{Al}$ Adl et al., on 162 PCNLs reported SFR was $75.9 \%$ and complication rate was $30.9 \%$. The mean acquisition time of scores was $05.1 \pm 0.3$ seconds for S.T.O.N.E. score and 102.6 \pm 3.5 seconds for S-ReSC score. Moreover, Operative Time (OT), Estimated Blood Loss (EBL) had best association with S-ReSC score [20]. All Al Adl et al., reported that all scores had comparable predictive accuracy on ROC curves regarding SFR. Stone essence and tract length are not different in cases with residual stones. Number of involved calyces, single vs multiple stones and renal pelvic obstruction were significant predictors of SFR in regression analysis [20].

A total of 157 PCNLs were reviewed by Bibi et al. The overall stone-free rate was 59\% (92/157) with a complication rate of $22 \%$ (35/157). Stone Burden $<542 \mathrm{~mm}^{3}$ is significantly associated with Stone-Free Rate (SFR) $(p=0.001)$. On univariate analysis, all the scoring systems were identified as significant factors in terms of SFR. S-ReSC score was associated with complications $(p<0.02)$ [21]. The initial stone-free and complication rates after TPCNL were $78.7(111 / 141)$ and $17.0 \%$
(24/141) in Choi et al., study. On univariate analysis, all scoring systems were identified as significant factors in terms of Stone-Free Rate (SFR) [22]. The area under the Receiver Operating Characteristic (ROC) curves for the S.T.O.N.E score and stone burden showed good results which was 0.816 [22].

ClevienDindo classification involving need for transfusion, fever and leakage. $65 \%$ of the included patients had no complications. The other 35 patients had different degrees of complications as shown in table. By running statistical analysis to find relation between mean of S-ReSC and STONE between different grades of ClevienDindo classification, no significant difference was found ( $p>0.05)$. In Al Adl et al., study, Clavien grade was associated with S.T.O.N.E. score. They also concluded that S.T.O.N.E. and S-ReSC scores were easily applicable and provided better association with blood loss and operative time [20]. The relatively small number of patients involved was a main limitation factor that would have influenced the confidence of statistical analysis of our data.

\section{Conclusion:}

Both S-ReSC and S.T.O.N.E Nephrolithometry Scores can be used to stratify the complexity of renal stone before PCNL to predict the stone clearance and complication. Both can be valuable tools for providing uniformity for comparison of outcome, proper planning of the surgery and preoperative counseling of the patient.

Conflicts of interest: No conflicts of interest were found.

\section{References}

1- ALELIGN T. and B. PETROS: Kidney Stone Disease: An Update on Current Concepts. Advances in Urology, p. 1-12, 2018.

2- KUMAR S., P. MISHRA and S. KUMAR: Ureteral obstruction by an aberrant renal artery: A case report. Indian Journal of Case Reports, 4 (6): p. 437-8, 2018.

3- SCALES C.D., et al.: Prevalence of Kidney Stones in the United States. European Urology, 62 (1): p. 160-5, 2012.

4- PFAU A. and F. KNAUF: Update on Nephrolithiasis: Core Curriculum. American Journal of Kidney Diseases. 68 (6): p. 973-85, 2016.

5- CHUNG K.J., et al.: Changing Trends in the Treatment of Nephrolithiasis in the Real World. Journal of Endourology, 33 (3): p. 248-53, 2019.

6- KYRIAZIS I., et al.: Complications in percutaneous nephrolithotomy. World Journal of Urology, 33 (8): p. 1069-77, 2014. 
7- BASIRI A., et al.: Neurologic Complications in Percutaneous Nephrolithotomy. Korean Journal of Urology, 54 (3): p. 172, 2013.

8- JEONG C.W., et al.: Seoul National University Renal Stone Complexity Score for Predicting Stone-Free Rate after Percutaneous Nephrolithotomy. PLoS ONE, 8 (6): p. e65888, 2013.

9- NOURELDIN Y.A., M.A. ELKOUSHY and S. ANDONIA.N.: Which is better? Guy's versus S.T.O.N.E. nephrolithometry scoring systems in predicting stone-free status post-percutaneous nephrolithotomy. World Journal of Urology, 33 (11): p. 1821-5, 2015.

10- OKHUNOV Z., et al.: S.T.O.N.E. Nephrolithometry: Novel Surgical Classification System for Kidney Calculi. Urology, 81 (6): p. 1154-60, 2014.

11- RATHI V., et al.: Ureteral Dilatation with No Apparent Cause on Intravenous Urography: Normal or Abnormal? A Pilot Study. Advances in Urology, p. 1-6, 2015.

12- EL-NAHAS A.R.: Editorial Comment on: Predicting the Post-operative Outcome of Percutaneous Nephrolithotomy with Machine Learning System: Software Validation and Comparative Analysis with Guy's Stone Score and the CROES Nomogram by Aminsharifi et al. J. Endourol., 2020.

13- HUANG W., et al.: Efficacy and safety of silodosin in the medical expulsion therapy for distal ureteral calculi: A Systematic review and meta-analysis. British Journal of Clinical Pharmacology, 81 (1): p. 13-22, 2016.

14- SHIN T.S., et al.: Complications of Percutaneous Nephrolithotomy Classified by the Modified Clavien Grading System: A Single Center's Experience over 16 Years. Korean Journal of Urology, 52 (11): p. 769, 2011.

15- LIATSIKOS E., et al.: “Angular Percutaneous Renal
Access". Multiple Tracts Through A Single Incision for Staghorn Calculous Treatment in A Single Session. European Urology, 48 (5): p. 832-7, 2005.

16- MUSLUMANOGLU A.Y., et al.: Impact of Percutaneous Access Point Number and Location on Complication and Success Rates in Percutaneous Nephrolithotomy. Urologia Internationalis, 77 (4): p. 340-6, 2006.

17- MAGHSOUDI R., et al.: Number of Tracts or Stone Size: Which Influences Outcome of Percutaneous Nephrolithotomy for Staghorn Renal Stones? Urologia Internationalis, 89 (1): p. 103-6, 2012.

18- AL-KOHLANY K.M., et al.: Treatment of Complete Staghorn Stones: A Prospective Randomized Comparison of Open Surgery Versus Percutaneous Nephrolithotomy. Journal of Urology, 173 (2): p. 469-73, 2005.

19- YARIMOGLU S., et al.: Comparison of S.T.O.N.E and CROES nephrolithometry scoring systems for predicting stone-free status and complication rates after percutaneous nephrolithotomy: A single center study with 262 cases. Urolithiasis, 45 (5): p. 489-94.

20- AL ADL A.M., et al.: Percutaneous Nephrolithotomy Outcomes Based on S.T.O.N.E., GUY, CROES, and SReSC Scoring Systems: The First Prospective Study. Journal of Endourology, 2020.

21- BIBI M., et al.: Les scores radiologiques peuvent-t-ils prédire le succès de la NLPC? Étude comparative du Guy's stone score, du STONE score, du CROES nomogram, et du S-ReSc score. Progrès en Urologie, 29 (8-9): p. 432-9, 2019.

22- CHOI S.W., et al.: Totally Tubeless Versus Standard Percutaneous Nephrolithotomy for Renal Stones: Analysis of Clinical Outcomes and Cost. Journal of Endourology, 28 (12): p. 1487-94, 2014. 


\section{التنبؤ بالنتائج الجراحيـة فيما يتعلق بمعلد الخلو من الحصوات والمضاعفات

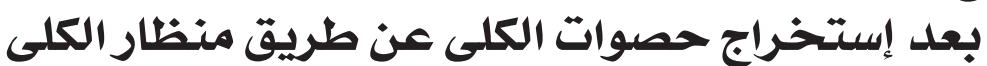

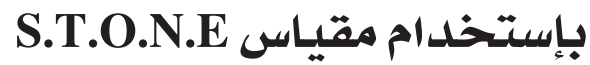 مقابل مقياس حصوات الكلى المتكامل SReSC}

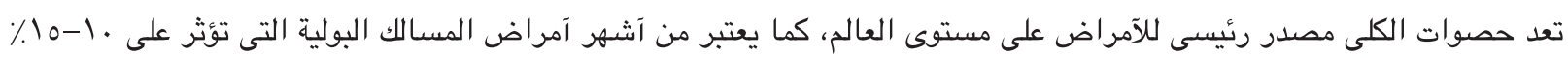

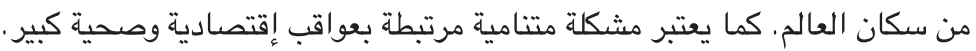

وتوفر التطورات التقنية للجراحين والمرضى العديد من الخيارات لعلاج الحصوات الكلوية، بما فى ذلك التفتيت بالموجات التصادمية

(ESWL)، وإستخراج الحصوات بمنظار الكلى (PCNL)، وإستخراج حصوات الكلى عن طريق منظار الحالب المرن، والجراحة التقليدية.

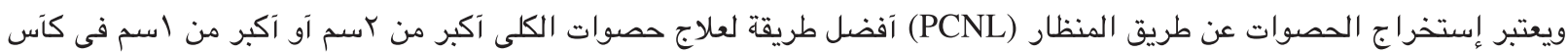

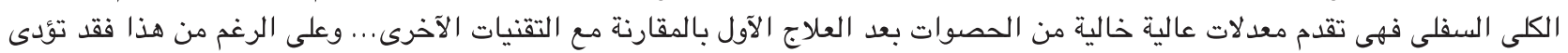

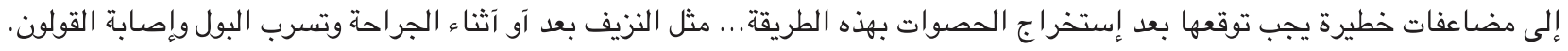
لذا فقد تم وصف معايير مقبوله عالمياً مثل مقياس ستون S.T.O.N.E ومقياس حصوات الكلى المتكامل S-ReSC وذلك لإستخدامها في

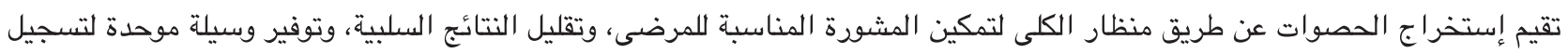
نتائج المريض.

إن مقياس ستون S.T.O.N.E. يحسب المعلومات الموجودة فى فحوصات التصوير المقطعى لوصف وتصنيف آكثر المعلومات ذات الصفي الصلة

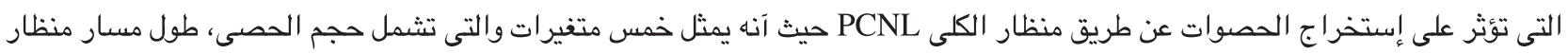

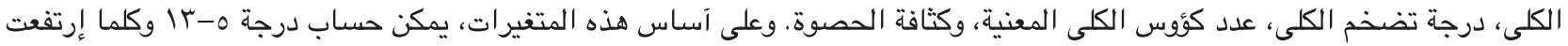
درجة المقياس كلما قلت نسبة خلو الكلى من الحصوات بعد العملية وزادت العنات نسبة المضاعفات.

كما يعتمد مقياس حصوات الكلى المتكامل S-ReSC فقط على توزيع الحصى داخل الكلى ولا يآخذ بعين الإعتبار آى خصائص اللمريض

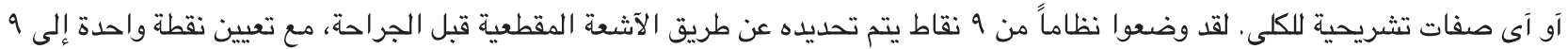

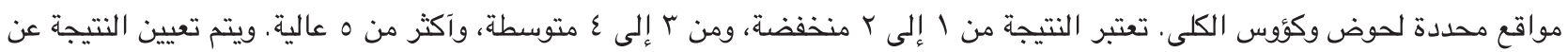
طريق إضافة المواقع التراكمية المعنية.

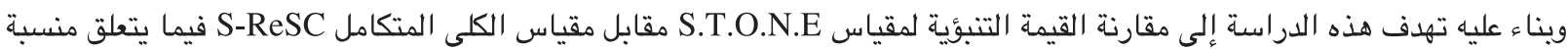

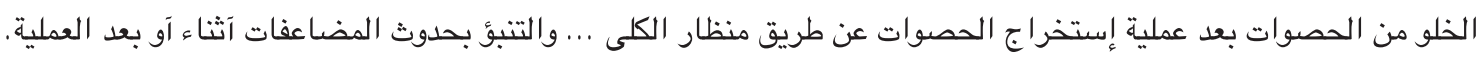

